\section{Spontaneous arousals from sleep in human subjects*}

\author{
G. W. LANGFORD, R. MEDDIS, and A. J. D. PEARSON \\ Bedford College, University of London, London NW1 4NS, England
}

Signaled arousals (SA) and unsignaled arousals (UA) from sleep were studied in nine Ss over 5 nights. The SA rate was highest in rapid eye movement (REM) sleep and lowest in Sleep Stage 4; SAs typically terminated REM periods. This pattern was not observed for unsignaled arousals. These results lend support to the theory (Snyder, 1966) that REM sleep serves a vigilance function. The results also call into question purely physiological criteria of arousal from sleep.

Arousals which occur during sleep are commonly considered to be brief failures of the mechanisms which maintain sleep. These may result from internal or external stimuli that occur essentially at random during the sleeping period. Such stimuli raise the level of arousal above the waking threshold, inducing a brief and typically quickly forgotten period of wakefulness. We may alternatively regard these arousals as preprogrammed interruptions of the sleep session. It has been suggested (Snyder, 1966) that these awakenings serve a vigilance function, especially in small mammals, where prolonged unconsciousness in a possibly hostile environment could prove seriously disadvantageous.

Many animals whose sleep is studied in the laboratory have frequent arousals which are linked into their sleep rhythm (Roldan et al, 1963; Kripke et al, 1967)-the alternation of slow wave sleep (SWS) ${ }^{t}$ with rapid eye movement sleep (REMS). Typically, the sleep cycle begins with a period of SWS which is followed by a period of REMS. The REMS may then give way to either more SWS or a brief arousal which often involves grooming and looking around. It could be that the REMS period serves to bring the cortical arousal level and the general physiological tone of the animal up to a high enough level to benefit from a brief arousal. Of course, not all REMS periods are terminated by arousals and not all arousals occur during REMS, but the pattern is strong enough to suggest that the REMS/SWS cycle does involve a regular waking episode.

The purpose of this experiment was to check whether the same considerations apply to the sleep of human Ss. It is commonly observed by sleep researchers that REMS periods are often terminated by brief arousals, but this has rarely been formally reported. If Snyder's vigilance hypothesis is correct, then we might expect the rate of spontaneous arousal to be higher during REMS than SWS.

* This work was assisted by a grant from the Medical Research Council.
If these arousals form part of the sleep cycle, then, by analogy with other mammals, we might expect them to terminate REMS rather than to occur in the middle of a REMS period. For the purpose of the experiment, we have defined arousals in two different ways. The first definition is in terms of physiological criteria and is based on measures of brain activity and muscle tension. The second definition is behavioral and concerns the ability of the $\mathrm{S}$ to inform the $\mathrm{E}$ that he is awake.

We thought that many disturbances of sleep might be responses to discomfort, involving changes of posture without concomitant arousals. Accordingly, on one night Ss were deliberately made uncomfortable. Discomfort, it was anticipated, would produce physiological signs of arousal without voluntary signaling.

\section{METHOD}

Nine Ss (four male and five female), drawn from the college student population, were invited to spend 5 consecutive nights in the sleep laboratory. All Ss were naive in that they had never before slept under such conditions. All-night continuous EEG, EOG, and chin EMG records were made and scored following standard procedures (Rechtschaffen \& Kales, 1968). Ss retired at their normal bedtime and were awakened $8 \mathrm{~h}$ later if they were not already awake. They were subjected to no interruptions or medication.

Each S slept with a small switch taped to his dominant hand and was invited to depress the switch for a few seconds whenever he was aware of being awake as soon as possible after waking. Depressions of the switch are referred to as signaled arousals (SA). The switch was an adapted Radiospares miniature microswitch. The lever had been removed, leaving a small button which required a switching force of $227 \mathrm{~g}$. The combination of the smallness of the button and the high switching force rendered accidental signals unlikely. Unsignaled arousals (UA) were judged to have occurred whenever the record manifested either $5 \mathrm{sec}$ of continuous alpha rhythm or $5 \mathrm{sec}$ of substantial muscle activity.

On one night-either the fourth or the fifth-the $S$ slept on a board which was placed between him and the mattress. Four Ss experienced this "hard bed" condition on Night 4 , the remainder on Night 5 .

\section{RESULTS}

Table 1 summarizes the distribution of sleep stages across the 5 nights of the experiment. This pattern corresponds well with other reports of the composition of sleep in adults (Williams, Agnew, \& Webb, 1964). Table 2 shows the total frequency of responding for all nine $S s$ in the various sleep stages. Arousals were signaled an average of five times per night in each $\mathrm{S}$. Unsignaled arousals (Table 3) occurred about 18 times per night.

Unsignaled arousals were just as frequent at the begiıning of the night as at the end. The total figures for successive quarters of the night were $181,215,204$, and $199\left(x^{2}=3.0\right.$, df $=3, \quad p>.05$ ). Signaled arousals gradually increased in frequency as the night progressed; $19,53,57$, and 75 $\left(x^{2}=32.2, \mathrm{df}=3, \mathrm{p}<.001\right)$. Clearly, the pattern over time of arousals differs according to the criterion used.

The distribution of the two types of arousal across the different sleep stages is also clearly different $\left(x^{2}=40.4\right.$, $\mathrm{df}=4, \mathrm{p}<.001)$. The $\mathrm{UA}$ rate remains fairly constant across the sleep stages though, not surprisingly, the highest rate is in Stage 1 . The difference

Table 1 Average Time (Minutes) Spent in Each Sleep Stage

\begin{tabular}{|c|c|c|c|c|c|c|c|}
\hline \multirow[b]{2}{*}{ Night } & \multirow{2}{*}{$\begin{array}{c}\text { Time } \\
\text { Awake }\end{array}$} & \multicolumn{4}{|c|}{ Time Spent in Each Sleep Stage } & \multirow[b]{2}{*}{ REM } & \multirow{2}{*}{$\begin{array}{c}\text { Total } \\
\text { Time } \\
\text { Asleep }\end{array}$} \\
\hline & & 1 & $\mathbf{2}$ & 3 & 4 & & \\
\hline 1 & 66 & 32 & 210 & 65 & 40 & 62 & 409 \\
\hline 2 & 31 & 29 & 220 & 40 & 45 & 98 & 432 \\
\hline 3 & 57 & 12 & 190 & 42 & $\mathbf{5 5}$ & 95 & 394 \\
\hline $\begin{array}{l}\text { Hard Bed } \\
(4 \text { or } 5)\end{array}$ & 32 & 15 & 197 & 45 & 52 & 102 & 411 \\
\hline $\begin{array}{l}\text { Control } \\
\text { ( } 4 \text { or } 5)\end{array}$ & 42 & 12 & 200 & $\mathbf{3 8}$ & 63 & 105 & 418 \\
\hline Means & 46 & 20 & 204 & 46 & 51 & 93 & 414 \\
\hline
\end{tabular}


Table 2

Total Number of Signaled Arousals for Nine Ss*

Sleep Stage

\begin{tabular}{|c|c|c|c|c|c|c|c|c|c|c|c|c|}
\hline \multirow{2}{*}{$\frac{\text { Night }}{1}$} & \multicolumn{4}{|c|}{2} & \multicolumn{2}{|l|}{3} & \multicolumn{2}{|l|}{4} & \multicolumn{2}{|c|}{ REM } & \multicolumn{2}{|c|}{ Totals } \\
\hline & 1 & (0.2) & 23 & $(0.7)$ & 3 & $(0.6)$ & 1 & $(0.2)$ & 16 & $(1.7)$ & 44 & (.7) \\
\hline 2 & 4 & $(0.9)$ & 22 & $(0.7)$ & 2 & $(0.3)$ & 2 & $(0.3)$ & 23 & (1.6) & 53 & (.8) \\
\hline $\mathbf{3}$ & 0 & $(0.0)$ & 14 & (0.5) & 2 & $(0.3)$ & 2 & $(0.2)$ & 17 & $(1.2)$ & 35 & (.6) \\
\hline $\begin{array}{l}\text { Hard Bed } \\
(4 \text { or } 5)\end{array}$ & 4 & (1.8) & 17 & $(0.6)$ & 2 & $(0.3)$ & 0 & $(0.0)$ & 21 & (1.4) & 44 & (.7) \\
\hline $\begin{array}{l}\text { Control } \\
(4 \text { or } 5)\end{array}$ & 0 & $(0.0)$ & 14 & $(0.5)$ & 0 & $(0.0)$ & 0 & $(0.0)$ & 15 & $(1.0)$ & 29 & (.5) \\
\hline Totals & 9 & $(0.6)$ & 90 & $(0.6)$ & 9 & (0.3) & 5 & $(0.1)$ & 92 & (1.3) & 205 & (.7) \\
\hline
\end{tabular}

*Figures in brackets indicate rates of responding (signals per hour).

Table 3

Total Number of Unsignaled Arousals for Nine Ss*

\begin{tabular}{|c|c|c|c|c|c|c|c|c|c|c|}
\hline \multirow{3}{*}{$\frac{\text { Night }}{1}$} & \multicolumn{9}{|c|}{ Sleep Stage } & \multirow[b]{2}{*}{ Totals } \\
\hline & \multicolumn{2}{|l|}{1} & \multicolumn{2}{|l|}{2} & \multicolumn{2}{|l|}{3} & \multicolumn{2}{|l|}{4} & REM & \\
\hline & 23 & (4.7) & 66 & (2.1) & 7 & (1.4) & $\mathbf{g}$ & (1.5) & $21(2.2)$ & 126 (2.1) \\
\hline 2 & & (3.9) & 74 & (2.2) & 8 & (1.3) & 16 & (2.4) & 35 (2.4) & $150(2.3)$ \\
\hline 3 & 13 & $(7.0)$ & 73 & (2.5) & 13 & $(2.0)$ & 17 & (2.1) & $48(3.4)$ & $164(2.8)$ \\
\hline $\begin{array}{l}\text { Hard Bed } \\
(4 \text { or } 5)\end{array}$ & & (4.0) & 91 & (3.1) & 11 & (1.6) & 26 & (3.3) & $52(3.4)$ & $189(3.1)$ \\
\hline $\begin{array}{l}\text { Control } \\
(4 \text { or } 5)\end{array}$ & & (3.9) & 73 & $(2.4)$ & 8 & (1.4) & 23 & (2.4) & $45(2.9)$ & $156(2.5)$ \\
\hline Totals & 69 & (4.5) & 377 & (2.5) & 47 & (1.6) & 91 & (2.4) & 201 (2.9) & $785(2.5)$ \\
\hline
\end{tabular}

*Figures in brackets indicate rates (arousals per hour).

between the two patterns remains significant even if Stage 1 scores are ignored $\left(x^{2}=15.5, \mathrm{df}=3, \mathrm{p}<.01\right)$.

Signaled arousals have a much higher rate of occurrence in Stage REMS than in any other sleep stage. In addition, the rate of signaled arousals during SWS is very much a function of the sleep stage. Stages 1 and 2 have the highest SA rate, while Stage 4 has the lowest. This is very much in keeping with currently held views concerning the different "depths" of SW sleep stages.

The discrimination between rate of arousal in REMS and SWS holds for signaled arousals but not for unsignaled arousals. The SA rate for REMS $(1.3 / \mathrm{h})$ is more than twice as high as that for SWS $(0.5 / \mathrm{h})$. The UA rate is more similar for REMS $(2.9 / \mathrm{h})$ and SWS $(2.3 / \mathrm{h})$. It should be noted at this point that five of the signaled arousals, while manifesting some signs of arousal, would have failed to meet the physiological criterion for an unsignaled arousal.

The distribution of signaled arousals during REMS periods was very much as predicted. More than $50 \%$ of the signaled arousals that occurred in REMS terminated the REMS period and were followed by SWS. Only 13\% of the signaled arousals in SWS occurred during the last $5 \mathrm{~min}$ before a REMS period.

A first night effect was in evidence (Agnew, Webb, \& Williams, 1966). Ss spent more time awake and less time in REMS on the first than on subsequent nights. The rate of unsignaled arousals was depressed on the first night, however, and this may possibly be attributed to the reduced time asleep. The hard bed condition produced an elevation of both signaled and unsignaled arousals over the control night, but these differences were not significant using a Subjects by Treatments analysis of variance.

\section{DISCUSSION}

The pattern of arousals predicted by Snyder's vigilance hypothesis was found for signaled but not unsignaled arousals. It is possible that the criterion for unsignaled arousals was too weak and included too many partial arousals. The fact that five signaled arousals did not meet this weak criterion argues against this explanation. Similarly, if the unsignaled arousal criterion had been strengthened by including only events showing $10 \mathrm{sec}$ of continuous alpha rhythm or substantial body movement, then a much larger number of signaled arousals would have failed the test. It seems likely that EEG/EMG criteria do not successfully discriminate between disturbances of sleep that are accompanied by awareness and those that are not. Some displays of consciousness (SA) did not meet the purely physiological criteria and, moreover, many events which satisfied the EEG/EMG criteria produced no signal. The discussion that follows will focus on signaled arousals which offer a better indication that the $S$ was awake and conscious of his environment.

The evidence presented supports the idea that the SWS/REMS cycle in man may be better described as a SWS/REMS/WAKE cycle. Our results show that the likelihood of a brief arousal from REMS is more than twice as great as that of an arousal from any stage of SWS. Furthermore, arousal from REMS is highly likely to terminate the REM period. The cycle is analogous to that found in laboratory studies of mammals.

of course, not all arousals from sleep are to be explained by this mechanism; more than $75 \%$ of all signaled arousals occur at times other than the termination of REMS. Additional explanations are required for these. Nor must we imagine that all REMS periods are terminated by signaled arousals. In our experiment only $25 \%$ of REMS periods followed this pattern. The evidence merely supports the idea that the mechanisms are present in man as in mammals, even though they are imperfect in operation.

Snyder's suggestion that REMS has a vigilance function is supported by these results. It is rewarding to view sleep in terms of one long spell of SWS which is interrupted by REMS at regular intervals. The purpose of the REMS period is to raise the physiological arousal of the animal in such a way as to prepare it for a brief awakening. When the awakening does occur, the animal is already alert and all physiological functions are ready for investigation and fight or flight. Once the awakening has occurred, the duty of the REMS has been discharged and, on returning to sleep, the animal returns to SWS. It is difficult to test the argument that REMS has evolved to serve a vigilance function, but it is clear that regular arousals during the course of sleep would be of survival value in a hostile environment, whether or not this is the only function served.

\section{REFERENCES}

AGNEW, H. W., JR., WEBB, W. B., \& WILLIAMS, R. L. The first night effect: An EEG study of sleep. Psychophysiology, 1966, 2, 263-266.

KRIPKE, D. F., REITE, M. L., PEGRAM. G. V., STEPHENS, L. M., \& LEWIS, O. F. Nocturnal sleep in rhesus monkeys. Electroencephalography \& Clinical Neurophysiology, 1968, 24, 582-586.

RECHTSCHAFFEN, A., \& KALES, A (Eds.) $A$ manual of standardized terminology, techniques and scoring system for sleep stages of human subjects. National Institute of Health Publication 204, Washington, D.C: U.S. Government Printing Office, 1968.

ROLDAN, E., WEISS, T.. \& FIFKOVA, E. Excitability changes during the sleep cycle of the rat. Electroencephalography 
\& Clinical Neurophysiology, 1963, 15, WILLIAMS, R. L., AGNEW, H. W., JR., \& 775-785.

SNYDER, F. Toward an evolutionary theory of dreaming. American Journal of Psychiatry, 1966, 123, 121-136.
WEBB, W. B. Sleep patterns in young a duits: An EEG study. Electroencephalography \& Clinica Neurophysiology, 1964, 17, 376-381.
NOTE

1. SWS is intended by the authors to cover Sleep Stages 2,3, and 4 (Rechtschaffen \& Kales, 1968). 